\title{
DOES SIZE MATTER? THE IMPACT OF TERRITORIAL FRAGMENTATION/ CONSOLIDATION ON PERFORMANCE OF LOCAL GOVERNMENTS
}

DOI: http://dx.doi.org/10.18509/GBP.2016.47

UDC: 352-027.1(4)

\author{
Prof. Dr. Pawel Swianiewicz \\ Dr. Julita Lukomska \\ University of Warsaw, Poland
}

\begin{abstract}
Recent years have revitalized debates about territorial amalgamation reforms in many European countries. Proponents of the reforms usually expect significant savings due to economy of scale and increased capacity for service delivery due to better human resources. But opponents claim that amalgamation deteriorates local democracy and some academic analysis suggest that predicted gains of territorial consolidation are exaggerated. Convincing, methodologically sound, empirical evidences are relatively scare. We use observations of actual territorial reforms as an opportunity for "semilaboratory experiment" allowing to assess the impact of change, through the Synthetic Control methodology. So far similar approach (using difference-in-difference method) has been applied to some territorial consolidation reforms in Europe (e.g. Denmark, Sweden). The paper studies Polish case. Paper analysis cases of 6 splits of county governments in 2002. The methodology is based on comparing trends of selected variables before and after the split. The "case counties" are compared with the control groups (or control unit), consisting of "the most similar cases" selected on the basis of multiple criteria. The dependent variables are spending on administration and operating surplus. Paper is based on results of the "Impact of Size on Efficiency of Local Governments" project financed by the grant from National Science Centre (grant number 236388, UMO-2013/11/B/HS4/01695).
\end{abstract}

Keywords: Local government, territorial reforms, economy of scale, local democracy.

\section{INTRODUCTION}

The issue of optimal territorial organization belongs to the most frequently discussed in academic literature on local governments [1]. But in spite of those numbers there is still far from univocal conclusions. But if we take into account the dominant tune of the debate, the "reform theory" arguing for territorial consolidation stresses first of all economy of scale and capacity to deliver wider scope of local public functions. On the other hand public choice theory advocating territorial fragmentation refers competition among local jurisdictions (,voting by feet”) and arguments related to local democracy. The classic, comprehensive summary of the debate may be found in M. Keating's study [11], who discusses four dimensions: efficiency of service delivery, local democracy, capacity to support local economic development and challenges of redistribution issues. This article focuses mostly on the first of this dimensions.

The issue of relationship between the size of local government and efficiency and effectiveness of its functioning met so far surprisingly low interest of empirical studies in 
Poland. The opinions on the number of municipalities or counties are usually based either on intuition (sometimes based on individual case study evidences) or very superficial analysis of statistical data. There is a lack of theoretically grounded and methodologically sound empirical studies. This paper attempts at contributing at filling this gap.

\section{SIZE OF LOCAL GOVERNMENTS AND COSTS - REVIEW OF LITERATURE} The conclusions of empirical study on the relationship between size and costs of service delivery are not fully univocal. One of the newest review of empirical evidence [12] covers 490 conducted studies (mainly American, but also several European and a few from other continents). The review summarizes that nearly half of studies could not find statistically significant relationship, but the remaining group confirmed existence of economy of scale, although relationship was often non-linear. But the impact of size on quality of delivered services is more doubtful.

The similar skepticism may be found in some World Bank reports, which state that population size is not a decisive factor. In particular, they argue that in case of sparsely populated areas territorial consolidation rarely leads to gains from economy of scale [6]. More sophisticated models conducted by Houlberg on Denmark [9] come to the conclusions that limited economy of scale effect can be seen in relation to schools, roads maintenance, daily care centres and administrative services, but in two latter cases effect is seen only below certain threshold (30 and 50 thousand respectively), while diseconomies of scale are seen for larger jurisdictions.

What is known from earlier research in Poland? Evidences are mostly limited to municipal level, sound researches on the county level are scarce. The study of Kachniarz [10] who - using very complex methodology - tries to compare effectiveness of counties in Lower Silesia region, is perhaps the only exception to this rule. Kachniarz comes to the conclusion that size of county does not matter for its performance, and relates it to the low role of constant in the total costs of public services. Hypothesis related to costs are included in the 2011 report prepared by the Ministry of Public Administration. The report argues that costs in small municipalities and counties are high and recommends territorial consolidation. But the conclusion is based on very simplistic data, single-dimensional analysis of the impact of size. E.g. it disregards that jurisdictions with the low number of residents are usually sparsely populated, which pushes-up costs regardless of the size of the unit ${ }^{5}$.

An important complicating factor may be also ,internal outsourcing" of some cost categories, which is more frequent in larger cities which provide several functions through municipal companies and other institutions, which spending is not reflected in the local budget [9]. On the other hand there are some functions which are financed by mid-size and large cities, but absent in the spending of most of small local governments (e.g. local public transportation systems). Kachniarz [10] demonstrates that even data related to the single and relatively simple service, as spending on administrative functions, have to be interpreted much more cautiously than it is usually done in Polish literature.

Testing economy of scale hypothesis is even more complex in relation to other local public functions. Reliable empirical studies are relatively scarce. Drew et al. [5] on the basis of their studies in Australia claim to confirm economy of scale in management of

\footnotetext{
${ }^{5}$ Similarly, in my recent study of Albanian municipalities I have discovered that variation of costs may be statistically better explained by population density, then by the size factor itself.
} 
parks, but not in local roads neither waste management ${ }^{6}$. Czako et al. [4] in research on Hungary confirm economy of scale in waste management and to a lower extent (only for jurisdictions below 5,000 population) in water-sewage services and central heating. But that study raises methodological doubts, in particular it concentrates on the mere relationship between size and costs, ignoring variation of outcomes as well as intervening factors, such as population density.

The review of literature confirms that verification of economy of scale hypothesis in relations to local public services is methodologically very complex. Complications are related to multiple intervening variables (such as population density, peripheral location, affluence of local communities) as well as to the method measurement of outcome (which should take into account not only costs, but also quality and impact of organizational solutions). Results of studies differ dependently on the scope of analysed services and methodological assumptions. In Poland there is a lack of in-depth studies, and popular opinions are weakly rooted in methodologically sophisticated analysis.

\section{METHODOLOGY - TERRITORIAL REFORMS AS RESEARCH LABORATORIES?}

Territorial reforms provide unique opportunity for empirical studies on the issues in focus of this paper. They may be treated as - rare in social sciences - laboratories enabling observation of the impact of independent variable (population size) on the dependent variable (cost of local services), which may be extracted from the impact of other, intervening variables. Recent years brought examples of similar analysis. A few of them concerned Australian reforms (e.g. [5]), but they do not utilize "laboratory conditions" in full, since they rely on regression analysis conducted on data concerning before and after territorial change. Analysis of historical data concerning territorial consolidation reforms in Sweden in $1950^{\text {th }}$ and $1970^{\text {th }}$ comes to the conclusions that amalgamation reform brought saving, but only in small municipalities (below 12,800 population) [7]. But the most interesting are perhaps studies of Danish 2007 reform, during which number of counties was reduced from 19 to 5 and municipalities from almost 300 to nearly 100 [3], [8]. In those researches sophisticated difference-in-difference method allows to compare changes in amalgamated local governments, with the "control group" of not affected units. Authors of analysis conclude that consolidation resulted in saving in administrative costs (but visible only after few years) and increase of operating surplus. At the same time they note loses in functioning of local democracy.

Is applying similar methods possible? Since 1975 Poland have not implemented any major consolidation reform neither on municipal (gmina) nor on county (powiat) level. Individual cases of mergers were extremely rare. But it is possible to investigate individual, but sufficiently numerous, opposite cases of territorial fragmentation. In particular in 1995-2010 there were 16 cases of splits of existing municipalities. But our paper concentrates on county level, which is easier to analyse since all splits occurred in the same moment.

\footnotetext{
${ }^{6}$ The last finding is surprising taking into account that waste management belongs to typical examples of scale economy in the European context. But one should remember that the environmental context, especially extremely low population density, is in Australia very different than in Europe, and that difference may influence the variation of costs of this service.
} 
Polish county government in its current from was created at the beginning of 1999 . Initially there were 308 counties (plus 65 cities of county status). In 2002 seven new counties were created by split from existing units. Our research focuses on 6 out of those 7 cases (we omit case of Łobez county, which is the most complex since the new unit was created from parts of three earlier existing counties). The mean population size just before the change was slightly over 100,000 and the median size was 78.8 thousand. Four out of six counties divided in 2002 were smaller than the mean population size, and three of them were below median size (see table 1). The split led to creation new units being among smallest counties in Poland. 11 out of 12 new counties were in 2002 below median population size, and 11 out of 12 were in the first decile.

Table 1. Names and size of new counties created in 2002.

\begin{tabular}{|c|c|c|c|}
\hline Name of the county before 2002 & $\begin{array}{l}\text { Population size } \\
2001 \text { (in ,000) }\end{array}$ & $\begin{array}{l}\text { Name of the county from } \\
2002\end{array}$ & $\begin{array}{l}\text { Population size } \\
\text { in } 2002(, 000)\end{array}$ \\
\hline \multirow{2}{*}{ Bieszczady } & \multirow{2}{*}{48.86} & Bieszczady & 22.34 \\
\hline & & Lesko & 26.60 \\
\hline \multirow{2}{*}{ Giżycko } & \multirow{2}{*}{85.22} & Giżycko & 57.05 \\
\hline & & Węgorzewo & 23.93 \\
\hline \multirow{2}{*}{ Łódż East } & \multirow{2}{*}{93.39} & Łódź East & 62.80 \\
\hline & & Brzeziny & 30.79 \\
\hline \multirow{2}{*}{ Malbork } & \multirow{2}{*}{105.03} & Malbork & 63.17 \\
\hline & & Sztum & 42.04 \\
\hline \multirow{2}{*}{ Nowa Sól } & \multirow{2}{*}{125.66} & Nowa Sól & 86.88 \\
\hline & & Wschowa & 38.76 \\
\hline \multirow{2}{*}{ Olecko-Gołdap } & \multirow{2}{*}{57.41} & Olecko & 34.38 \\
\hline & & Gołdap & 27.18 \\
\hline
\end{tabular}

Source: own calculations based on Main Statistical Office data (www.stat.gov.pl).

In our experiment we look at new units from the point of view of two variables illustrating changes in costs of service delivery: per capita spending on local administration and per capita operating surplus of the budget. We analyse not only spending just before and just after the change, but we look at longer trends. Taking into account longer period before the reform is justified by the Blom-Hansen [2] observation of untypical spending behaviour just before the reform (e.g. higher spending, less conservative borrowing policies), which is related to the fact that long-term consequences would be carried-out by the local governments of newly created units (so called common pool problem) ${ }^{7}$. Analysing longer period after reform might be explained by transaction costs of the reform itself, which may distort short-term trends (in our experiment we cover 2002-2014 period, i.e. 13 years after the reform).

Instead of difference-in-difference (as in Danish experiments) we use Synthetic Control method. The essence of the method is finding for each case of the „reformed county” the "control group" (or "control unit") - for each treated county the method construct one synthetic control unit, an abstract construct built on the basis of value of few counties which used to be the most similar before the change. The more similar to our "treated case" is a county the higher its weight is in the value of dependent variables in the synthetic control unit. The criteria of similarity include our dependent variables as well

\footnotetext{
${ }^{7}$ In our case the ,pre-reform period" is limited to relatively short 1999-2001 time-span, since county governments did not exist before that date. The analysis for municipal level would allow to follow longer time series.
} 
as population size, population density, wealth of local community (per capita local tax base) and location in the same (NUTS-1) region. We compare the trend of dependent variables in the counties which experienced territorial change with the "control unit" of the most similar cases. That should allow us to extract the impact of size change, assuming that other factors (such as wealth of local community, population density etc.) remain the same.

\section{RESULTS}

Not surprisingly, in none of analysed cases, the split of counties resulted in saving on administrative costs (which would be a sign of diseconomy of scale). Just opposite, in all cases the reduced size of counties resulted in higher per capita spending on local administration. However investigated cases differ from each other. In three of them (reforms resulting in creation of Gołdap, Wschowa, Węgorzewo counties) the effect is long-lasting, visible throughout the whole 2002-2014 period. The more dramatic seem to be consequences of division of Nowa Sól county (creation of a new Wschowa unit) - the cost became visibly higher than in the control unit immediately and the gap has been gradually growing throughout next years. In two other cases (creation of Brzeziny and Sztum counties) the effect is very clear immediately after reform, but it slowly disappears during following ca. 10 years. The case of Lesko (separated from the Bieszczady county) is a bit more complex. The negative effect is not very clear for first two years but then the gap (comparing to the control unit) appears and sustains for another few years. In Sztum the difference from the control unit becomes minimal already in 2008 (six years after the changes), while in Brzeziny and Lesko it evaporates about 2012 (ten years after reform). But it is very striking that in the short and medium term the cost paid by local communities (in the form of increased spending on administration) could be seen in all analysed cases. The summary picture (based on mean for all six analysed cases) is presented on figure 1. The picture is a bit more complex in case of changes in operating surplus. The changes are more dramatic and sometimes the trend line looks a bit chaotic ${ }^{8}$. Nevertheless, the summary picture (see fig. 2) shows clearly that the financial standing of divided counties was worsening, comparing to the control unit, especially in the first two years after the change, and it had been continuously worse for another at least five years. In 2003 (two years after the fragmentation reform) typical of new units ran in red (operating deficit) which was never a case of the control unit.

\footnotetext{
${ }^{8}$ Fluctuations of the operating surplus (deficit) may be to a large extent explained by changing economic situation in Poland as well as by the evolution of the both public finance system (e.g. tax policies) and precise allocation of tasks among tiers of public administration. But these issues go beyond the scope of this paper and therefore are not discussed in details.
} 


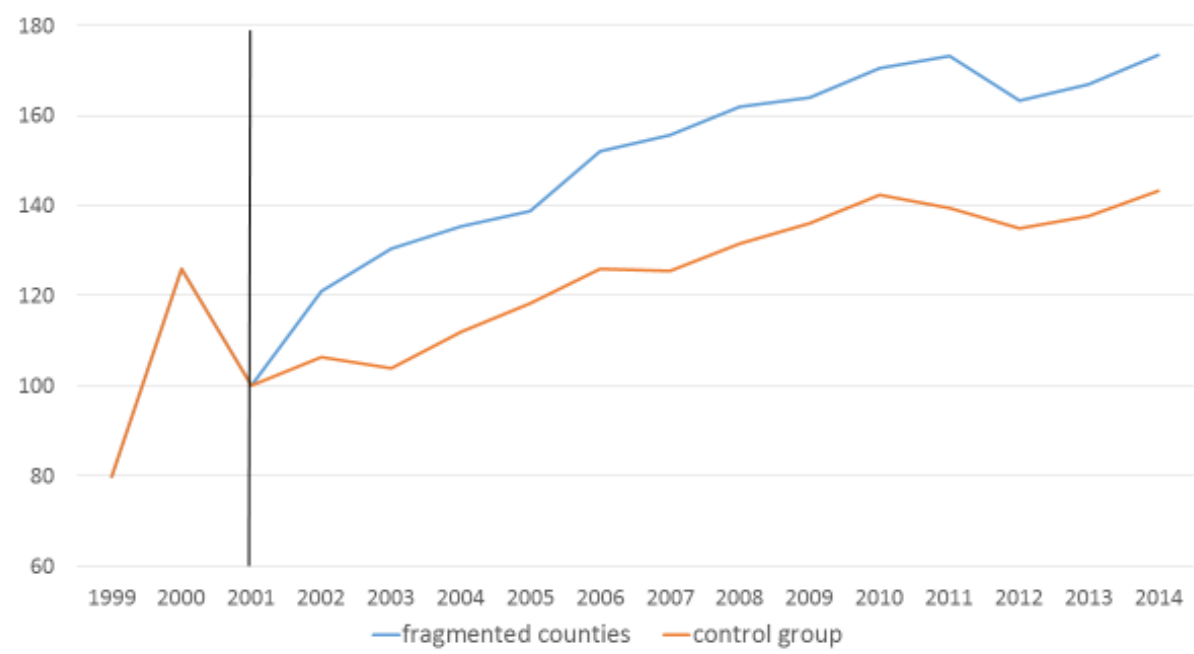

Figure 1. Per capita spending for administration - mean for 6 counties fragmented in 2002 (constant prices, 2001=100)

Source: own calculations based on budget execution data (provided by Ministry of Finance)

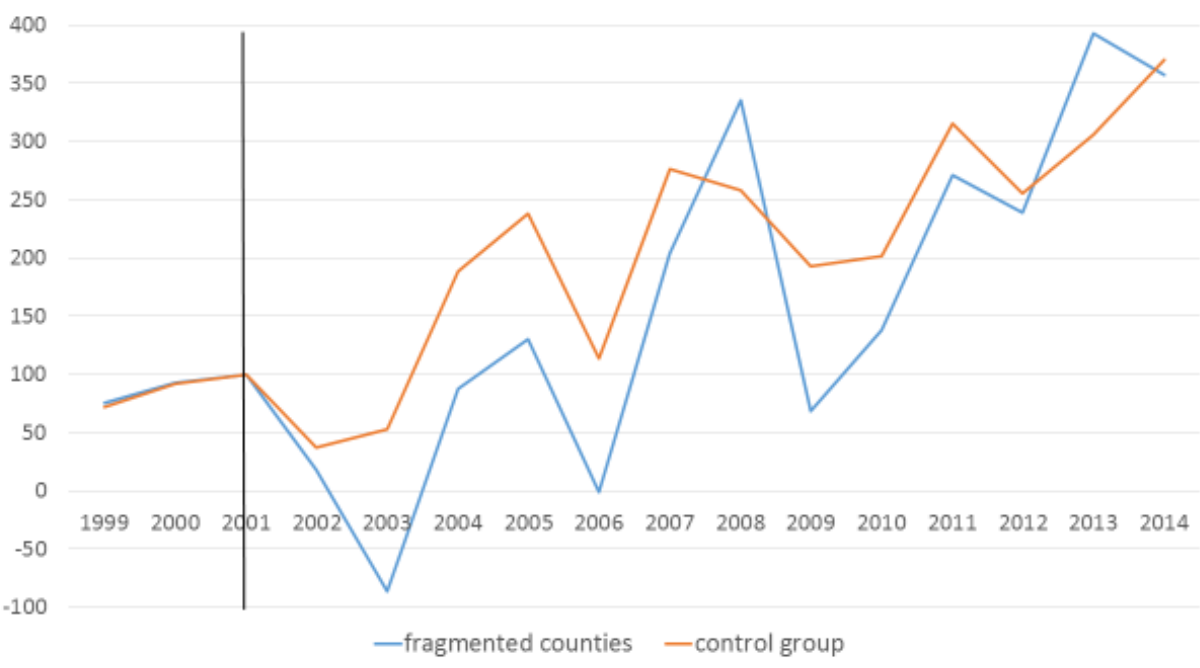

Figure 2. Per capita operating surplus - mean for 6 counties fragmented in $2002(2001=100)$

Source: own calculations based on budget execution data (provided by Ministry of Finance)

But once again the picture is more diversified if we look at individual cases. In two out of six analysed splits (leading to creation of Gołdap and Lesko counties) the negative impact on operating surplus sustained in the mid-term of about 8 years (and is especially strong in case of division of Olecko-Gołdap into Olecko and Gołdap counties). In three other (leading to establishment of Brzeziny, Malbork and Węgorzewo counties) the negative effect was weaker (perhaps with exception for Węgorzewo) and lasting shorter period of about 5 years. In one case of division of Nowa Sól county (creation of a new Wschowa county government) there is no visible impact of change on the size of operating surplus (but no positive impact either, which - as proponents of territorial fragmentation might argue - would be result of either diseconomy of scale or better policies of smaller, more homogenous and closer to people jurisdictions). It is striking that the only case with no clear effect on operating surplus concerns the largest of six 
divided counties, and the newly created units are not so small as in most of other analysed cases. It suggests non-linear economy of scale relationship, but it would be premature to formulate far going conclusions on the basis of a single case among limited number of analysed splits. The issue should be studied more thoroughly in the future.

\section{CONCLUSIONS}

The results presented in this paper clearly confirm, contested in some of earlier studies (in Poland studies of Kachniarz, e.g. [10], but also some publications related to other countries) economy of scale effect in the conduct of Polish county financial management. It is true at least in relationship to costs of local government administration, and operating surplus of the budget which to a large extent is a derivative of the general costs of provided services.

But we should be aware of the limits in with generalization of these results. First, we do not think that it is justified to directly extrapolate that conclusion to municipal level as well. There are several reason for that reservation. First, the size of municipalities is usually much smaller, so the shape of the scale effect may be different. Second, Polish municipalities are much more autonomous in the management of their finance than counties, so the policy outcomes might be different. Last but not least, municipalities are responsible for different set of functions, and - as discussed in the initial sections of the paper - the size impact might be different depending on the nature of the service. Therefore, the municipal size issue requires a separate investigation ${ }^{9}$.

Finally, the importance of our conclusions for policy recommendations on the optimal territorial organization is meaningful, but also limited. We would not argue that results presented in this case provide already sufficient arguments for territorial consolidation of the county tier or even and argument against individual cases of territorial fragmentation. There might be other gains related to the small size of local governments, which have not been covered by our study so far, such as gains related to better functioning of local democracy. That has to be investigated separately in the future. But identified negative effects of fragmentation (and of the small-size of the counties in general) should be clearly communicated to national and local level policy makers and to local communities debating number and size of their territorial jurisdictions.

\section{REFERENCES}

[1] Baldersheim, H. \& Rose, L. Territorial Choice: The Politics of Boundaries and Borders, London: Palgrave-Macmillan, 2010.

[2] Blom-Hansen, J. Municipal amalgamations and common pool problems: the Danish local government reform in 2007, Scandinavian Political Studies, vol. 33, pp 51-73, 2009.

[3] Blom-Hansen, J., Houlberg, K. \&, Serritzlew, S. Size, democracy and economic costs of running the political system, American Journal of Political Science, vol. 58, pp. 790803, 2014.

[4] Czako, K., Duse, T., Koppány, K., Poreisz, V. \& Szalka, É. Economies of scale in local communal services in Hungary, Regional Statistics vol. 4, pp. 16-27, 2014.

\footnotetext{
${ }^{9}$ Which is a part of research agenda of authors of this paper. Results of this study will be available late in Spring 2016.
} 
[5] Drew, J., Kortt, M. \& Dollery, B. Did the big stick work? An empirical assessment of scale economies and the Queensland forced amalgamation program, Local Government Studies, vol. 42, pp. 1-14, 2016.

[6] Fox, W.F., Gurley, T. Will Consolidation Improve Sub-National Government, Policy Research Working Paper 3913, Washington: World Bank Report, 2005.

[7] Hanes, N. Amalgamation impacts on local public expenditures in Sweden, Local Government Studies, vol. 41 pp. 63-77, 2015.

[8] Hansen, S.W., Houlberg, K. \& Pedersen, L.H. Do municipal mergers improve fiscal outcomes?, Scandinavian Political Studies , vol. 37, pp. 196-214, 2014.

[9] Houlberg, K. Municipal Size, Economy, and Democracy [in:] P. Swianiewicz (ed.) Territorial Consolidation Reforms in Europe, Budapest: LGI - Open Society Institute, 2010.

[10] Kachniarz, M. Efektywność ustug publicznych - teoria i praktyka, Wrocław: Wydawnictwa Uniwersytetu Ekonomicznego, 2012.

[11] Keating, M. Size, Efficiency and Democracy: Consolidation, Fragmentation and Public Choice [in:] D. Judge, G. Stoker, H. Wolman (eds.) Theories of Urban Politics, Sage, London- Thousand Oaks - New Delhi, 1995.

[12] Walker, R.M. \& Andrews, R. Local government management and performance: a review of evidence, Journal of Public Administration Research and Theory, vol. 25, pp. 101-133, 2013. 